Section Editor

John J. Millichap, MD

Mystery Case:

\title{
Acute hydrocephalus caused by radiographically occult fourth ventricular outlet obstruction
}

Daniel Duran, MD*

Muhamed Hadzipasic, MD*

Kristopher T. Kahle, MD, $\mathrm{PhD}$

Correspondence to

Dr. Kahle:

kristopher.kahle@yale.edu

\section{Figure 1 Acute hydrocephalus associated with functional obstruction of 4 th ventricular CSF outflow}

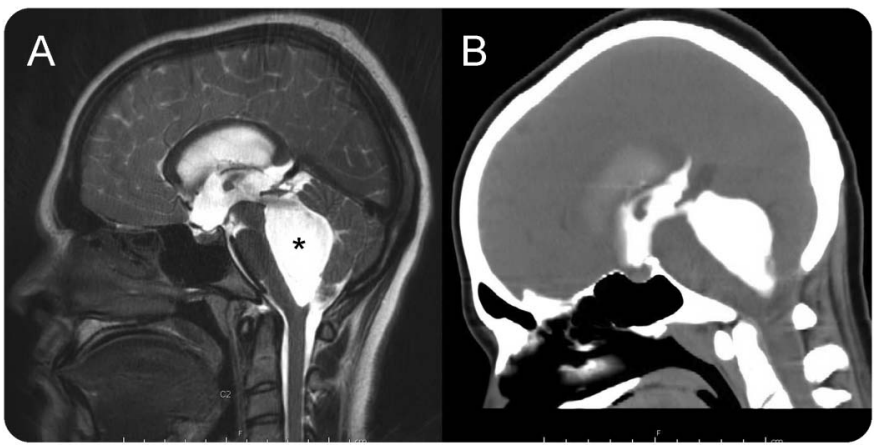

(A) Sagittal T2-weighted MRI demonstrates ventriculomegaly. The asterisk highlights prominent fourth ventricular dilation, ventral displacement of the brainstem, and dorsal displacement and thinning of the cerebellum. (B) Sagittal CT ventriculography shows flow of contrast from the 3 rd to the 4 th ventricle, and absence of flow into the spinal subarachnoid space.

A 19-year-old woman with no history of CNS inflammatory pathology or hemorrhage presented with 5 days of diplopia and headache. Examination revealed papilledema and bilateral sixth nerve palsies. Imaging demonstrated panventricular enlargement and marked 4th ventricular dilation (figure 1). Cine MRI revealed turbulent fourth ventricle CSF flow suggesting outflow obstruction, which was confirmed with contrast ventriculography. A suboccipital craniotomy was then performed, which revealed an arachnoid web (figure 2). Membranous occlusion of the fourth ventricular outlet is a rare cause of obstructive hydrocephalus usually associated with a history of inflammatory conditions or hemorrhage. ${ }^{1}$ A small number of idiopathic cases have been reported. ${ }^{2}$

In this case, microsurgical fenestration reconstituted CSF flow and resolved the patient's diplopia. However, she subsequently required ventriculoperitoneal shunting to resolve recrudescence of persistent headache, indicating both obstructive and communicating components to her hydrocephalus syndrome.

\section{AUTHOR CONTRIBUTIONS}

Daniel Duran: construction of figures and text. Muhamed Hadzipasic: construction of figures and text. Kristopher T. Kahle: concept and design, performed suboccipital craniotomy, microsurgical fenestration procedure, acquired photographic images, critical revision of text and figures.

\section{STUDY FUNDING}

No targeted funding reported.

\section{DISCLOSURE}

The authors report no disclosures relevant to the manuscript. Go to Neurology.org for full disclosures.

\section{REFERENCES}

1. Longatti P, Fiorindi A, Martinuzzi A, Feletti A. Primary obstruction of the fourth ventricle outlets: neuroendoscopic approach and anatomic description. Neurosurgery 2009;65: 1078-1086.

2. Karachi C, Le Guèrinel C, Brugières P, Melon E, Decq P. Hydrocephalus due to idiopathic stenosis of the foramina of Magendie and Luschka. J Neurosurg 2003;98:897-902.

\section{MYSTERY CASE RESPONSES}

The Mystery Case series was initiated by the Neurology ${ }^{\circledR}$ Resident \& Fellow Section to develop the clinical reasoning skills of trainees. Residency programs, medical student preceptors, and individuals were invited to use this Mystery Case as an educational tool. Responses were solicited through a group e-mail sent to the American Academy of Neurology Consortium of Neurology Residents and Fellows and through social media. We received 177 responses. The vast majority of respondents (73\%) had been in practice for 1-4 years; $53 \%$ were residents/fellows while $32 \%$ were faculty/

*These authors contributed equally to this work.

From the Departments of Neurosurgery (D.D., K.T.K.), Pediatrics (K.T.K.), and Cellular and Molecular Physiology (K.T.K.), Yale School of Medicine (M.H.), New Haven, CT. 


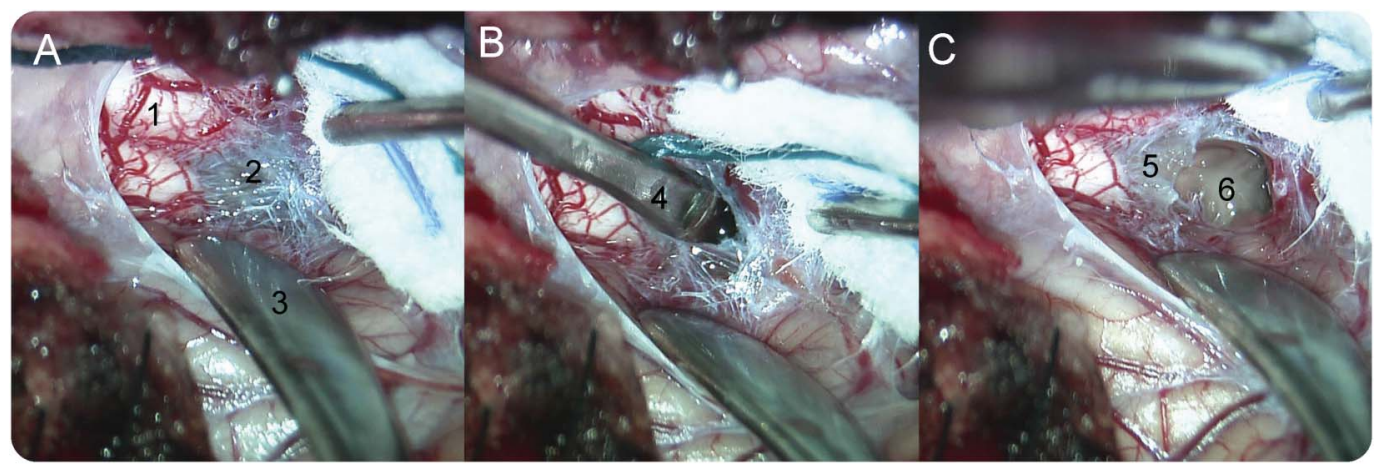

(A) Arachnoid web at the level of the cerebellomedullary junction (4th ventricular outlet). (B) Fenestration of arachnoid web. (C) Postfenestration. (1) Medulla. (2) Dense arachnoid web obstructing fourth ventricular outlet and obscuring the obex. (3) Dissector retracting the right cerebellar tonsil. (4) Penfield dissector fenestrating the arachnoid web and projecting into the fourth ventricle (5) Remnant of arachnoid web. (6) Area postrema on the floor of the fourth ventricle.

board-certified physicians. Seventy percent resided outside the United States. A wide range of practice settings was represented.

Eighty percent of the respondents correctly identified the basic MRI features of this case, which included dilation of the lateral, third, and fourth ventricles. Fifty-six percent also identified the additional important findings of ventral displacement of the brainstem and dorsal displacement of the cerebellum, which likely contributed to the patient's presenting complaint of diplopia. Twenty-six percent also identified the crucial finding of absent contrast flow in the spinal subarachnoid space on CT ventriculography. However, only $11 \%$ correctly identified the most likely diagnosis in this case: an arachnoid web causing obstructive hydrocephalus. The most commonly selected diagnosis was aqueductal stenosis (23\%), followed by colloid cyst (19\%) and choroid plexus papilloma (15\%). While these 3 are important differential diagnoses to consider in a presentation of obstructive hydrocephalus, the key to clinching the diagnosis in this case is the dilation of the patient's fourth ventricle, which means that the obstruction (if any) must be downstream of the fourth ventricle. This rules out a colloid cyst (classically seen in the third ventricle), choroid plexus papilloma (typically in the lateral ventricles), and aqueductal stenosis (which affects the cerebral aqueduct connecting the third and fourth ventricles). ${ }^{1}$ Typically, the observation of fourth ventricle dilation simply leads to a diagnosis of communicating hydrocephalus, but in this case, CT ventriculography showed absence of contrast flow into the spinal subarachnoid space, leading to suboccipital craniotomy and an intraoperative diagnosis of an arachnoid web.

This case highlights the importance of interpreting neuroimaging findings of hydrocephalus in the context of the anatomy of the ventricular system.

Aravind Ganesh, MD

Department of Clinical Neurosciences, University of Calgary, Canada; and Centre for Prevention of Stroke \& Dementia, Nuffield Department of Clinical Neurosciences, University of Oxford, UK

\section{REFERENCE}

1. Pople IK. Hydrocephalus and shunts: what the neurologist should know. J Neurol Neurosurg Psychiatry 2002; 73:i17-i22. 


\section{Neurology}

\section{Mystery Case: Acute hydrocephalus caused by radiographically occult fourth ventricular outlet obstruction}

Daniel Duran, Muhamed Hadzipasic and Kristopher T. Kahle

Neurology 2017;88;e36-e37

DOI 10.1212/WNL.0000000000003555

This information is current as of January 30, 2017

\section{Updated Information \&} Services

References

Subspecialty Collections

Permissions \& Licensing

Reprints including high resolution figures, can be found at: http://n.neurology.org/content/88/5/e36.full

This article cites 3 articles, 1 of which you can access for free at: http://n.neurology.org/content/88/5/e36.full\#ref-list-1

This article, along with others on similar topics, appears in the following collection(s):

Cerebrospinal Fluid

http://n.neurology.org/cgi/collection/cerebrospinal_fluid

Hydrocephalus

http://n.neurology.org/cgi/collection/hydrocephalus

Information about reproducing this article in parts (figures,tables) or in its entirety can be found online at:

http://www.neurology.org/about/about_the_journal\#permissions

Information about ordering reprints can be found online:

http://n.neurology.org/subscribers/advertise

Neurology ${ }^{\circledR}$ is the official journal of the American Academy of Neurology. Published continuously since 1951, it is now a weekly with 48 issues per year. Copyright @ 2017 American Academy of Neurology. All rights reserved. Print ISSN: 0028-3878. Online ISSN: 1526-632X.

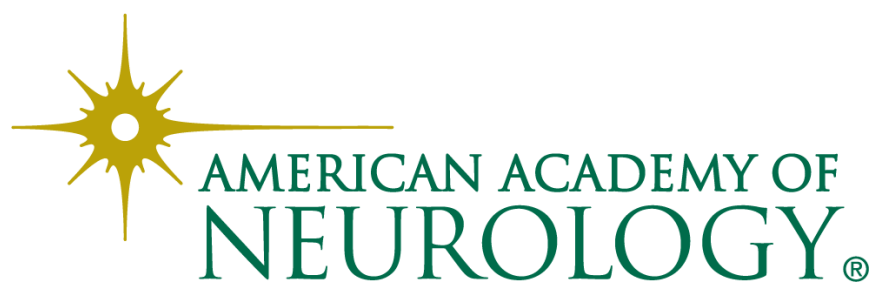

